Article

\title{
Space for Climate
}

\author{
Pierre-Philippe Mathieu
}

ESA/ESRIN, Via Galileo Galilei, 64, Frascati 00044, Italy; E-Mail: pierre.philippe.mathieu@esa.int; Tel.: +39-069-418-0568

Academic Editors: Christoph Aubrecht and Wolfgang Kainz

Received: 12 June 2015 / Accepted: 12 August 2015 / Published: 1 September 2015

\begin{abstract}
This paper describes how Earth Observation (EO) data-in particular from satellites - can support climate science, monitoring, and services by delivering global, repetitive, consistent, and timely information on the state of the environment and its evolution. Some examples are presented of EO demonstration pilot projects performed in partnership with scientists, industry, and development practitioners to support climate science, adaptation, mitigation, and disaster risk management. In particular, the paper highlights the challenge of gathering observations and generating long-term climate data records, which provide the foundation of risk management. The paper calls for a science-based integrated approach to climate risk management supported by data and knowledge, providing decision-makers with a unique analytical lens to develop a safety net to risk and maximize opportunities related to climate change and variability.
\end{abstract}

Keywords: Earth Observation; ESA Satellite Missions; Climate; Global Climate Observing System; ECVs; Geo-information services

\section{Climate Change as a Development Challenge}

We live on a rapidly changing planet, with a global population racing toward a projected 9 Billion people by 2050 , and nearly 3 Billion expected to join the middle class in the next two decades [1]. This leads to an exploding demand for food-water-energy commodities, resulting in enormous and unsustainable pressures on natural resources such as water and arable land. In addition, climate change induced by human activities is causing an additional significant stress on our life-support ecosystems services.

Humans are now the dominant driver of large-scale changes on the environment with impact at the global scale, moving our planet into an entirely new geological epoch, the "Anthropocene" [2]. Climate 
change is one of the most important human-induced global changes. From high carbon emissions to ocean acidification, from rising temperatures to sea level rise and ice melting, from climate extremes to impact on ecosystem services, climate change is presenting us with quite an uncertain future for securing food-water-energy nexus resources. The recent Fifth Assessment Report of the Intergovernmental Panel for Climate Change (IPCC) [3,4] recalled the urgent need for collective actions to keep the world within the agreed $2{ }^{\circ} \mathrm{C}$ warming boundaries. The World Bank Group states in its Turn Down the Heat reports $[5,6]$ that under current Greenhouse Gas emissions pledges, mankind is in fact "en route" towards a $4{ }^{\circ} \mathrm{C}$ warmer world by the end of this century, with devastating impacts on agriculture, water resources, ecosystems, and human health.

Climate Change has now become central to our sustainable development challenge, as it can undermine development gains and put billions of people at risk, in particular for the most vulnerable in poor countries. The links between development and climate change have now become clear and unavoidable. Extreme climatic events could reverse years of development success in developing countries.

Enhancing resilience of our society to natural hazards and climate change, while developing a sustainable low-carbon economy are now among the greatest global challenges we face. These challenges are at the heart of the post-2015 development agenda, and associated Sustainable Development Goals (SDGs), which for the first time recognizes our life-support ecosystem services as a pre-requisite for any development if deemed to become sustainable [7].

\subsection{The Need for an Integrated Risk Management Approach}

To address these challenges, a truly science-based Integrated Risk Management approach is needed to better manage the risks and capitalize on the opportunities related to both human-induced climate changes and natural climate variability.

Such integrated approach would require accurate quantification of hazards intensity, vulnerability, and exposure of populations and assets. It would also require a new type of "nexus" thinking, acknowledging that there are other aspects of risk contributing to the overall global change risk, such as the direct impact of human activities (e.g., coastal flood flooding risk depends on both sea-level rise and subsidence from water pumping), and the cascading risks resulting from the inherent relationships between climate and the water-food-energy resources.

The idea of an integrated risk management approach is not new but is gaining more momentum within the scientific community. Recent reports of the IPCC [3,4] are advocating for a science-based evidence-based risk approach in order to be able to make informed decisions under uncertainties, design robust early warning systems, and ultimately objectively define an optimal "safety net" to transfer risks of climate-sensitive sectors. The most recent report of Working Group II of the IPCC features the Water/Energy/Food/Feed/Fibre Nexus as linked to Climate Change as a cross-chapter theme. The nexus also features in the SDGs through an integrated approach.

Adopting an integrated risk management approach should hopefully lead to climate-smarter decisions at various levels for a wide variety of end-users, ranging from businesses to the public sector up to citizens, bringing their information needs into a unified risk framework. It would help decision-makers to better handle synergy and trade-offs between different interconnected risks related to climate, water, energy, and food security and co-design solutions to address them. Recognizing that 
climate change is at the heart of development, Multilateral Development Banks, such as the World Bank Group, are now developing tools to support climate risk screening enabling them to better identify risk "hot spots" and prioritize their areas of actions and investment.

\subsection{The Need for an Integrated Earth Observing System}

One of the key foundations for managing risks lies in the observations. These provide the basis for any scientific understanding, from the testing of hypothesis to the detection of anomalies, from the development and validation of models to the attribution and prediction of climate change.

At the same time, decision-makers require accurate, consistent, and timely information about the state of our changing environment and its evolution to form and inform their decisions regarding adaptation and mitigation strategies.

Building a full picture of a rapidly changing and interconnected environment of our planet over a wide range of scale in space-from local to global-and time-from minutes to decades-requires a comprehensive Integrated Global Earth Observing System of Systems (GEOSS) fusing data from multiple sources including in situ networks, drones, a web of sensors, and satellite imagery.

The need for a "Data Revolution" combining all types of open data with high tech to achieve the post-2015 SDGs has been recently called for by the UN Secretary-General's Independent Expert Advisory Group on a Data Revolution for Sustainable Development [8].

EO from space plays a key role in this endeavor as satellites are uniquely placed to deliver the comprehensive, global, and consistent data sets needed to support climate observation, research, and services.

By remotely sensing radiation, EO satellites are able to derive information on some of the key climate parameters. This capability goes well beyond simple pretty pictures (being already very useful) to become a powerful quantitative tool. Using the unique vantage point of space, satellites deliver global data, covering even the most remote places where no survey data exist or are possible to obtain. The ability to retrieve historical data from the satellite archive is also a key advantage to allow users to detect changes in the environment. These unique characteristics of wide-area mapping of EO data make them particularly useful to complement-but not supplement-traditional in situ measurements, which are typically point based, sparsely distributed, or simply completely missing in remote or difficult to access areas (e.g., mountains, polar regions).

Over the last decades, rapid advances in our capability to observe our planet has led to enormous scientific insight into how our climate works as part of a complex coupled system. In particular, EO satellites have played a vital role in advancing Climate Science and supporting the IPCC as they are uniquely placed to capture a global, consistent, and repetitive view of our home planet, resulting in major discoveries from the global sea-level rise to the Antarctic ozone hole.

Today, more than a hundred EO satellites, carrying multiple radar and optical instruments, are continuously monitoring the state of our planet, providing scientists with a continuous stream of data on the state of the ocean, atmosphere, ice sheets, and vegetation.

With the launch of Sentinel-1 in 2014 - the first in the series of operational satellites - and Sentinel-2 in 2015 (sentinel.esa.int), and the advent of the Copernicus initiative, Europe has entered a new era for the development and exploitation of open EO data. Copernicus will provide a unique global 
observational capability to Europe across the whole electromagnetic spectrum and across a wide range of applications. These sustained observations will be complemented by exploratory measurements derived from a series of research Explorer missions dedicated to Earth system science (www.esa.int/eo). For more information on the satellite missions worldwide and their applications, see the recent handbook of the Committee on Earth Observation Satellites (CEOS) prepared for Rio+20 (eohandbook.com).

\section{Earth Observation Data for Climate Monitoring}

The importance of global and sustained observations for monitoring climate and its changes has long been recognized by the United Nations Framework Convention on Climate Change (UNFCCC) (article $4.1 \mathrm{~g}$ ). In this context, the Global Climate Observing System (GCOS) was established in 1992 to better quantify the information needs of the UNFCCC. In particular, GCOS has defined a set of Essential Climate Variables (ECVs) required to quantify the state of our climate and related forcing.

GCOS also calls for a systematic generation of long-term, homogeneous and continuous Climate Data Records (CDRs) of the ECVs together with a measure of their uncertainty and a documentation of the process. One of the most convincing examples of the value of CDRs, which now epitomizes the issue of climate change and has significantly driven its political agenda, is the continuous record of atmospheric composition of $\mathrm{CO}_{2}$ compiled by Keeling at the station of Mauna Loa (Hawaii) since 1958. This simple curve revealing a continuous rise of $\mathrm{CO}_{2}$ has forever changed our vision on the global impact of human-induced activities by unambiguously establishing the connection between the burning fossil fuel and the increase of atmospheric $\mathrm{CO}_{2}$.

Generating CDRs however remains an enormous challenge. The process requires piecing together large amount of heterogeneous observations, coming from multiple sources (both from in situ and remote sensing), and made for multiple purposes (both research and operational applications), but in most cases not originally designed for climate. The different observational streams-referred to here as Fundamental Climate Data Records (FCDRs) — often lack the coverage and level of accuracy and most importantly stability needed to capture small climate signals over long time periods. This can lead to problems if the data set is used for monitoring climate, as some of the climate-related signals (typically smaller than day-to-day natural weather variability) could be masked out. Another concern is the lack of continuity of some of the FCDRs data streams, in particular the ones derived from research infrastructures, often lacking sustained funding, and therefore not guaranteeing proper maintenance or replacement of aging instruments. This can result in gaps in the CDRs, which are often irreversible as we get only one chance to record it. Generating CDRs therefore needs by nature sustained observations, and therefore sustained funding for observing systems.

EO satellites can play a key role in monitoring climate as they provide global and consistent observations for some of the ECVs ranging from Sea Surface Temperature (SST), Sea-level, Cloud, Aerosols, up to vegetation health and chemical composition of the atmosphere. This unique role of EO for climate data has been further recognized by the GCOS in the satellite supplement of its Implementation Plan, which identified the space-based observations requirements to deliver a sub-set of ECVs having a strong satellite component.

International efforts by space agencies worldwide under the auspice of CEOS are also actively ongoing to contribute to the GCOS. However, given that the majority of satellites contributing to the 
GCOS have not been designed specifically for monitoring climate, it can create problems (e.g., gaps, spurious jumps or offsets due to changes in observing systems characteristics), and is therefore necessary to continuously re-process the data archive in the context of new knowledge to achieve the climate quality and accuracy required by GCOS.

One effort in Europe to create CDRs is the ESA Climate Change Initiative (CCI). The data from ESA missions archive are re-processed iteratively in several cycles, corrected for any contamination (e.g., effect of city on temperature), re-calibrated and re-validated with reference data sets, and judiciously interpreted for their various nature and error characteristics, in order to generate high-quality CDRs together with a measure of their error. The outstanding challenges for generating CDRs are of particular concern for satellites, which after having experienced the rigor of launch, have to operate in a very hostile and harsh environment, where no regular repair and maintenance of aging instruments is possible, and where absolute calibration traceable to accepted international standards remains extremely challenging. This makes the generation of CDRs from EO data a very specific issue, in particular to address the difficulty of achieving absolute accuracy, the decay and drift of orbits and aging of sensors.

Some examples of the use of EO data are given below to illustrate how EO supports the science of climate change, including the monitoring of climate variability, the understanding of the driving processes, the attribution of their causes and the prediction of their future impacts. They also illustrate how iterative re-processing of the record, taking account of progress in knowledge, accuracy, resolution, and user feedback are an integral part of the process of creating CDRs.

\subsection{Global Warming of the Upper Ocean}

The globally averaged Surface Temperature is today the major indicator of global warming. The global Sea Surface Temperature (SST), which represents two thirds of the global contribution, is therefore of critical importance to quantify the global effect of climate change. The SST is also very important to support ocean and atmospheric modelling, initialize prediction, and constrain re-analysis.

Long-term data sets of the SST however present important unwanted bias due to frequent changes in the observing system technologies (e.g., upgrade of sensors) or their drawback (e.g., aging sensor, bio-fooling of buoys, satellite drift). For example, the switch of technology from canvas buckets to wooden buckets, introduced a bias leading to a drop of SST between 1890 and 1940 due to the enhanced insulation induced by the wooden bucket. In contrast, the transition from sailing ships to powered vessels after 1940, lead to a sharp increase in SST as people were then using the seawater collected to cool the engines.

All these wanted or un-wanted changes can result in "artificial" signals in the CDR, which can in turn lead to spurious interpretation of climate trends. This implies that CDRs must be continuously re-processed, using the latest algorithms and bias correction techniques, to improve the accuracy of the CDRs. 


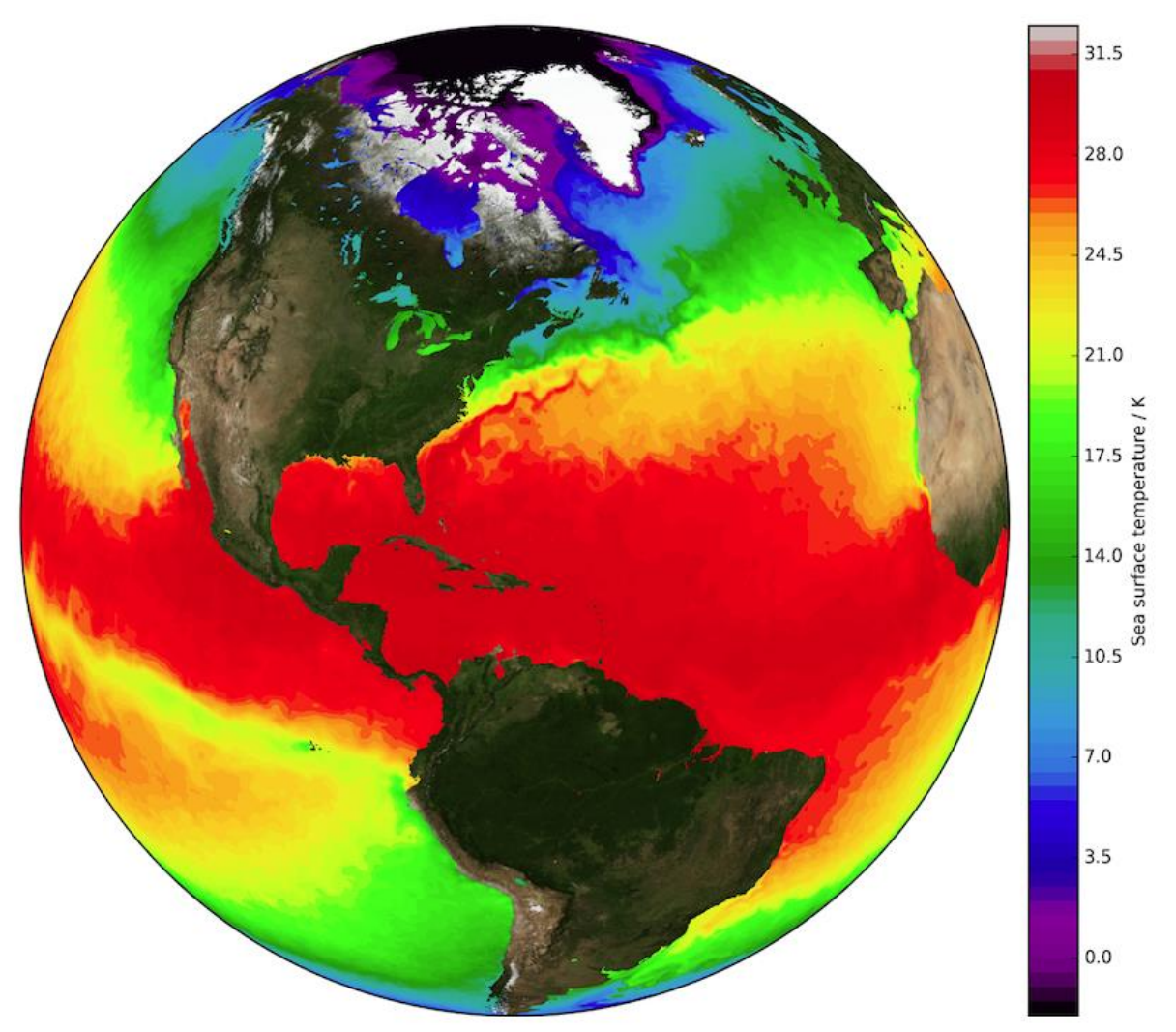

Figure 1. Global Sea Surface Temperature (SST) during La Nina (October 1998). Globally complete analysis of SST, synthesized from infra-red observations made by meteorological and research satellites. The analysis is a $0.05 \mathrm{deg}$ resolution in latitude and longitude and is daily. See [9].

In this context, the CCI SST ECV (Figure 1) has been designed specifically for climate applications, with very stringent requirements regarding accuracy and stability in line with GCOS needs, while trying to ensure a high degree of "independence" from other data sets (e.g., in situ buoys, models). The CCI SST record of 19 years (1991-2010) at $0.05 \mathrm{deg}$ resolution, has been derived from diverse EO-based SST observations, combining data from the series of three ESA Along-Track Scanning Radiometers (ATSRs), bringing a high level of accuracy and stability thanks to the sensor dual view, with data from the Pathfinder Advanced Very High Resolution Radiometer (AVHRR), providing extensive coverage in space and time. New algorithms (e.g., cloud screening, radiative transfer) and methodologies (e.g., anchoring of AVHRR data) have been developed to achieve the incredible accuracy of $0.1 \mathrm{~K}$ needed to support climate studies and quantify regional and global trends of about $0.2 \mathrm{~K} /$ decade.

\subsection{Global and Regional Sea-Level Rise}

The Sea-Level record is also one of the most important indicators of climate change, integrating the response of many components of the climate system, including thermal expansion of water, and melting of ice and glaciers. 
Space Altimetry started in 1975 with the launch of radar altimeter on board GEOS-3, which detected the sea surface height changes from gravitational effects over major trenches. The launch of Seasat in 1978, which only lasted for 105 days, proved the concept that by observing the ripples over the ocean surface from $800 \mathrm{~km}$ height, it was possible to see eddies signature and infer the "currents" and their main driving force the wind from space. It led to the development of higher-precision altimeters, with better technology and orbit determination, starting with the launch of Geosat (1985), followed by missions from Esa, such as ERS-1 (1991), ERS-2 (1995) and Envisat (2005) including an altimeter package (with radiometers for the water vapour correction), and U.S.-French missions such as Topex/Poseidon (1992), and operational missions such as Jason, culminating with the recent launch of the new generation of altimeter missions Cryosat-2 (2009). Over the last decades, precision was constantly improved due to better orbit determination, and better atmospheric correction (dual-frequency altimetry for reducing errors due to ionospheric effects), improving to the incredible accuracy of a few mm. Radar altimetry in the open ocean is now a mature science, and missions are operational (e.g., Jason).

The sea-level data record has provided scientists with a unique insight into the large-scale circulation of the ocean and its highly energetic meso-scale eddies, while revealing at the same time the global rise of sea-level and its regional details. Fifteen years of data have taught us more on ocean dynamics than two centuries of scientific expedition, revealing a plethora of new-and often unexpected-processes, such as mesoscale variability internal tides and sea-level rise, and also highlighting linkages, referred as tele-connections, between changes in atmospheric circulation occurring in widely separated parts of the globe. Also, the emergence of consistent global data records longer than two decades, has revealed the modes of spatial and temporal variability of the ocean, from the inter-annual (e.g., ENSO) to the decadal time scale (e.g., North Atlantic Oscillation, Pacific Decadal Oscillation, and Indian Ocean Dipole), pointing to the issue of global sea level rise and its regional details.

The ESA CCI has delivered a 18 years CDR of sea-level (Figure 2) based on data from seven high-precision altimetry missions, including ERS-1/2, Envisat, TOPEX/Poseidon, Jason-1/2 and GFO. Merging the different data sets has enabled to reach the incredible accuracy of a few $\mathrm{mm} / \mathrm{decade}$, which is needed to assess trends as small as mm/decades. About 50 algorithms have been developed and tested, addressing challenging issues such as precise orbit determination and coastal and high latitudes altimetry. The CCI products include both monthly mean Sea Level Anomalies at 0.25 deg resolution and indicators of Regional and Global Mean Sea Level change. The accuracy of the data set is likely to be further improved by new geodetic data from the gravity mission GOCE, while its continuity should be ensured by future high-precision altimetry missions, such as Sentinel 3, Cryosat-2, and the Jason series.

Attributing the causes of sea-level rise to melting of glaciers, ice sheet or thermal expansion remains a grand challenge for the research community. In particular, ice-sheet melting induces the biggest potential risk of global sea level rise (e.g., up to $7 \mathrm{~m}$ for the Greenland Ice Sheet). However, despite a large body of scientific studies based on both models and observations, there remain major uncertainties regarding ice sheet mass balance. In particular, there are three different independent measurement techniques from space supporting ice sheet mass balance including (i) altimetry measuring ice volume change; (ii) radar interferometry measuring ice drift and iceberg calving and (iii) gravimetry measuring changes in the Earth mass. These different techniques however lead to different results owing to inconsistencies in spatial and temporal sampling, and limitations of the technique itself. To address this 
issue, ESA in partnership with NASA has set up the Ice-sheet Mass Balance Inter-comparison Exercise (IMBIE), which aims to better understand and reconcile the discrepancies between the different measurement techniques by comparing them on a common observation period 2003-2008. IMBIE brought together 47 participants from more than 27 international laboratories to investigate measurement from more than 10 satellites. The study showed that, when domains match, techniques concur and are complementary, pointing to a total sea level rise of $11.1 \mathrm{~mm}$ within $3.8 \mathrm{~mm}$ error (about $20 \%$ of total sea level rise) induced by melting of Greenland (about 2/3) and Antarctica (about 1/3) since 1992, with a recent acceleration in the rate of melting. These data have provided unique insight into the ice sheet mass balance and the wider sea-level budget.

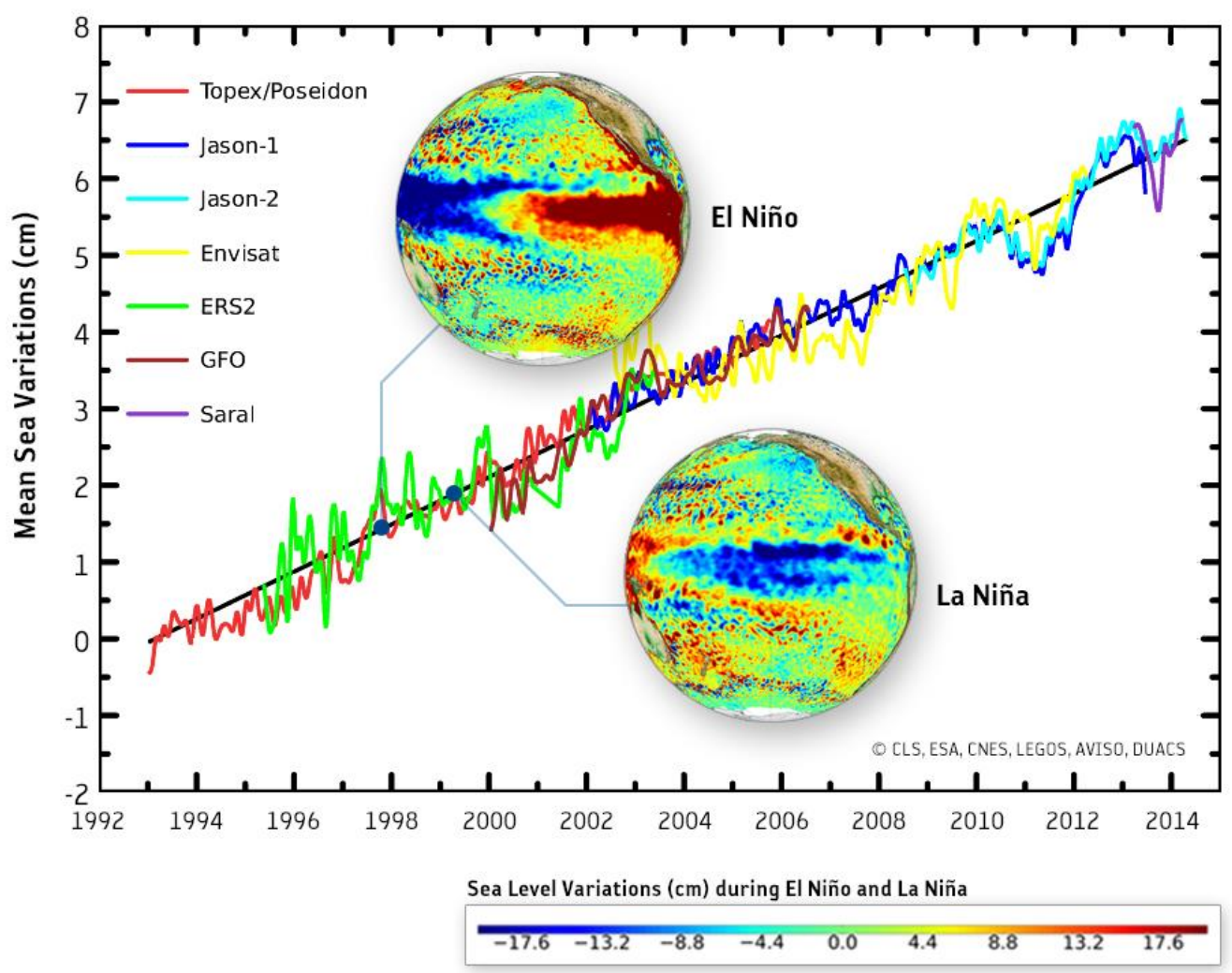

Figure 2. Global trend in mean Sea Level (in $\mathrm{cm}$ ) as derived from a series of altimeters on different satellites. Sustained observations are essential to understand the processes that can lead to long-term trends in the Earth system and to discriminate between long-term trends induced by human activities and shorter-term natural variability (e.g., El Niño, La Niña). Sustained observations are also vital to turn scientific advances into sustainable services for the benefit of society. Courtesy CNES/ESA/LEGOS/CLS/PPM.

These data and evolution of technologies, such as data assimilation and ocean state estimation, have now matured to a point where estimates of the global ocean state and its evolution-referred as 
operational oceanography — are achieved routinely, paving the way towards a new generation of maritime services.

\section{Earth Observation Data for Climate Services}

The demand for Climate Services is rapidly growing. Many public and private sectors, including insurance, agriculture, health, energy, and transportation, are increasingly needing information on the specific climate risks they face in order to guide their strategic plans, investments and policy decisions.

The Global Framework for Climate Services (GFCS) established in 2009 during the third World Climate Conference acknowledges observations and monitoring as an essential pillar of Climate Services, along with research, modeling, prediction, service information system, user interface, and capacity building [10].

One of the key challenges of Climate Services is to convert raw climate data into "actionable" information deemed useful for the end-users. Such data-to-information conversion process is not an easy task and inherently depends on the type of applications and targeted sectors. Many barriers and challenges still exist to make this conversion valuable (e.g., lack of awareness from the user on available capabilities, poor understanding of real user needs and requirements by the data providers). Delivering the right information often requires integration of EO data with other types of data, e.g., from models (e.g., re-analysis, climate projections), in situ observational networks (anyway needed to validate satellite data), socio-economic indicators and local knowledge. For example, energy companies would need to integrate climate information with energy demand projections to accurately forecast the load demand and improve planning of energy supply. Another challenge is to bridge over "the last mile" to the end-users. This often requires seamless integration of climate information into the user software and decision-making system, and possibly new ways of delivery such as mobile devices.

Climate Services also present very challenging requirements inherent to their climate nature, related to characterization of uncertainty, traceability (e.g., of documentation, processing), qualification of accuracy and integrity of information, and complexity of ingesting probabilistic risk information.

Climate Services are also about prediction (i.e., forecast) and projection (i.e., scenarios). Today, thanks to rapid progress in observing technology, coupled climate modelling, data assimilation techniques, and computing power, climate scientists are able to predict seasonal-to-decadal variations of the climate with some level of skill. They use also long-term climate simulations to develop projections about the future, such as the Coupled Model Intercomparison Project (CMIP) simulations. In this context, observation becomes increasingly important to initialize, validate, and constrain model simulations, becoming more complex (e.g., representing/parameterizing more processes) and operating at higher resolution (e.g., eddy-resolving ocean models) and regional scale (e.g., CORDEX).

Europe is now very active in the development of Climate Services with the recent advent of the European Copernicus Climate Change Service (C3S) supported by the European Commission within the framework of the Copernicus initiative. The C3S managed by the ECMWF includes elements such as the generation of CDRs, the development of long-term climate re-analyses, the assessment of the state of climate and the prediction of its changes, and the wide distribution of data to the community through a Climate Data Store to stimulate research and the service market. 
The value of Climate Service information is immense, and sometimes several times larger than the investment in the observing system. For example, the current annual cost of responding to natural disasters is about USD $\$ 6$ billion, and that projection suggests that the cost could increase to up to USD $\$ 1$ trillion a year by the year 2050 [11].

Quantifying these risks will benefit a variety of key industrial sectors affected by climate change, including health, water supply and sanitation, energy, transport, industry, insurance, mining, construction, trade, tourism, agriculture, forestry, and fishery, thereby resulting in major socio-economic benefits. These benefits will likely drive a huge demand for services and open a broad market to provide customized high-added-value services to a variety of users.

In the following section, we discuss some limited examples of EO-based information services supporting adaptation and mitigation of climate change, with focus on key issues such as food security, energy, and urban development. These are pre-cursor elements of a wider and more complex integrated risk approach to climate change [12,13].

\subsection{Climate-Smart Agriculture}

Farmers are now facing unprecedented challenges and pressures to meet the growing global demand for food (e.g., crops for food and livestock) and energy (e.g., biofuel demand), while most of the limited fertile land available on the planet is already used for intensive agricultural productivity. Meeting these needs lead to huge impacts on the water-energy food nexus, as global food production is expected to increase by $35 \%$, water by $40 \%$, and energy by $50 \%$ by 2030 [14]. In the meantime, 1 billion people remain chronically hungry today.

On top of that, climate change induced by human activities is causing additional stress on agricultural production and water resources (e.g., $70 \%$ of freshwater is used for agriculture), due to increased frequency and magnitude of extreme events (e.g., floods/droughts) or changes in environmental conditions (e.g., early flowering in certain plants, spread of pathogens and pests). Such extreme events are more likely in a warmer world, and people in already vulnerable living conditions will be hit hardest.

Another impact of climate is its effect on the market food price and recurring spikes. In particular, climatic extreme events such as floods and droughts, can induce significant volatility in the crop market, thereby suddenly putting several millions people into poverty. As a result, the risk of social unrest is growing. For example, in areas that do not have sufficient domestic grain production, and which are thus dependent on imports, the problem is quickly exacerbated as grain prices rise. For example, the 2007-2008 food protests in Tunisia and Egypt, among others, are considered an important factor in the Arab Spring. This issue of volatility of the crop market has lead the G20 to initiate the Agricultural Market Information System (AMIS) inter-agency platform, which aims to enhance international market transparency by improving the quality, timeliness, and reliability of food market information.

All these inter-connected challenges of food security lie at the heart of Climate-Smart Agriculture (CSA) aiming to develop precision farming strategies for maximizing agricultural production while minimizing impact on the environment and irrigation (e.g., less drops per crops) under a climate stress. One good example is the rapid development of innovative micro-insurance schemes to protect small farmers in Africa against climate fluctuations [15]. 
EO can play an important role here. The Global Agricultural Monitoring (GEO-GLAM) initiative aims to coordinate satellite monitoring observation systems in different regions of the world in order to enhance crop production projections and weather forecasting data. Within this framework, GEO-GLAM has developed a unique global crop monitoring capability, providing users with a multi-source consensus assessment of four primary crop types (wheat, maize, rice, and soy) in support of the AMIS market monitoring activities. One example is the monitoring of rice in Asia (Figure 3), where Sentinel-1 imaging radar enables the rapid and continuous assessment of the state of rice production and associated flooding. Global monitoring of crops by different sources of EO is a key building block of a wider integrated risk management system for CSA and food security. In this context, Sentinel-2 will provide a unique global and systematic view of our land vegetation at unprecedented resolution of $10 \mathrm{~m}$.

The convergence of open climate data with rapid advances in digital technologies (e.g., cloud, internet, mobiles) is likely to drive new innovation in climate services for agriculture and other sectors.

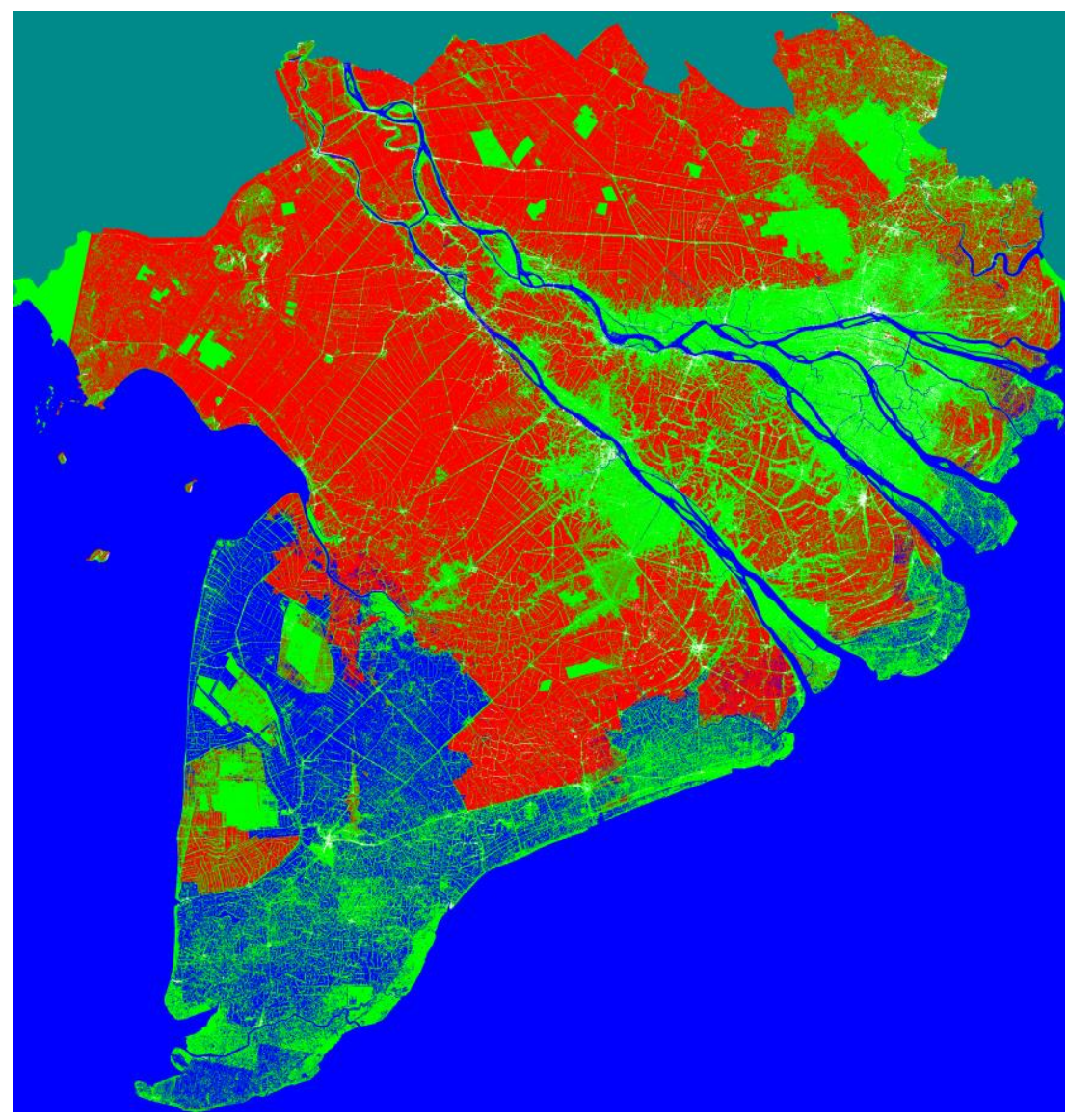

Figure 3. Land-cover map in the Mekong River Delta (Vietnam) for the 2015 spring-summer rice season derived from Sentinel-1A data (mode IWS). The land-cover map at $20 \mathrm{~m}$ resolution features rice production (red), non-rice (green) (e.g., other land use type such as trees, orchards, and other crops), water bodies (blue) (including sea, river, aquaculture), and land outside the Mekong delta (grey). The total rice planted area during this rice season is estimated to be 2.14 Million hectares by 21 July 2015. Copernicus Sentinel data (2015)/ESA/CESBIO/STAC/VAST/Asia-RICE/DUE. 


\subsection{Assessment of Renewable Energy Resources}

Wind energy is experiencing one of the fastest growths across the whole Renewable Energy industry. The financial success of wind farms is strongly bound to the wind resources available over the plant life-time (hence the revenue) but also to other factors affecting the initial investment such as the impact on environment, access to turbines for maintenance, and connection to the grid network for distribution (hence the cost). Quantifying these factors is critical to perform technical and financial feasibility studies of prospective sites but also to secure long-term investment.

The traditional way to assess the potential energy yield of a prospective wind farm is by using data from a meteorological mast, which is very expensive in terms of installation and maintenance. Although this approach is very accurate, it can only provide point-measurement data for a short period of time (typically one year), while the wind field is generally highly variable in space and time. This issue is further compounded for offshore farms, as the amount of wind offshore is sometimes estimated from on-shore measurements. Using local data can therefore be an issue to effectively assess the "bankability" of prospective farms.

In contrast, satellites can measure wind in a synoptic manner, but only over sea through active sensors, like scatterometers, altimeters, and Synthetic Aperture Radar (SAR). EO data thereby provides a more comprehensive and spatially resolved view of the ocean wind climatology and the entire probability distribution (Figure 4). The new generation of algorithms is now able to extract more information on wind magnitude and direction from the radar Doppler signal.

EO radar missions such as Sentinel-1 can provide users with information on coastal wind availability, the state of ocean (e.g., wind/wave met-ocean conditions), and land (e.g., roughness, vegetation cover). These missions now ensure continuity of such data streams for decades, with high revisit time of a few days over Europe and polar regions. This information will be critical to assist decision-making regarding operability and availability of wind turbines.

Other operational user-driven missions, like the Meteosat family in geostationary orbit, are delivering a wealth of information on availability of natural resources including a variety of renewable energy resources such as solar power. For example, Meteosat Second Generation (MSG) satellites deliver global maps of irradiance up to $1 \mathrm{~km}$ resolution every $15 \mathrm{~min}$. By combining EO-based irradiance maps with other EO products, such as Digital Elevation Model and cloud cover and aerosols maps, it is possible to estimate the solar energy yield expected from a solar energy power plant. The ability to go back in time in the archive of Meteosat data—spanning several decades-provides the long-term time series and statistics of direct/diffuse solar irradiance together with cloud conditions necessary to quantify solar resources. This information forms the basis of a portfolio of Climate Services supporting solar energy managers in siting, designing, and assessing performances of solar plants, such as the Copernicus downstream services developed. The future generation of meteorological missions such as the Meteosat Third Generation (MTG) to be launched within this decade will further improve these services by providing decision-makers with enhanced sampling capability in space, time and spectral range. 


\section{Sentinel-1}

Wind inversion - ESA IPF

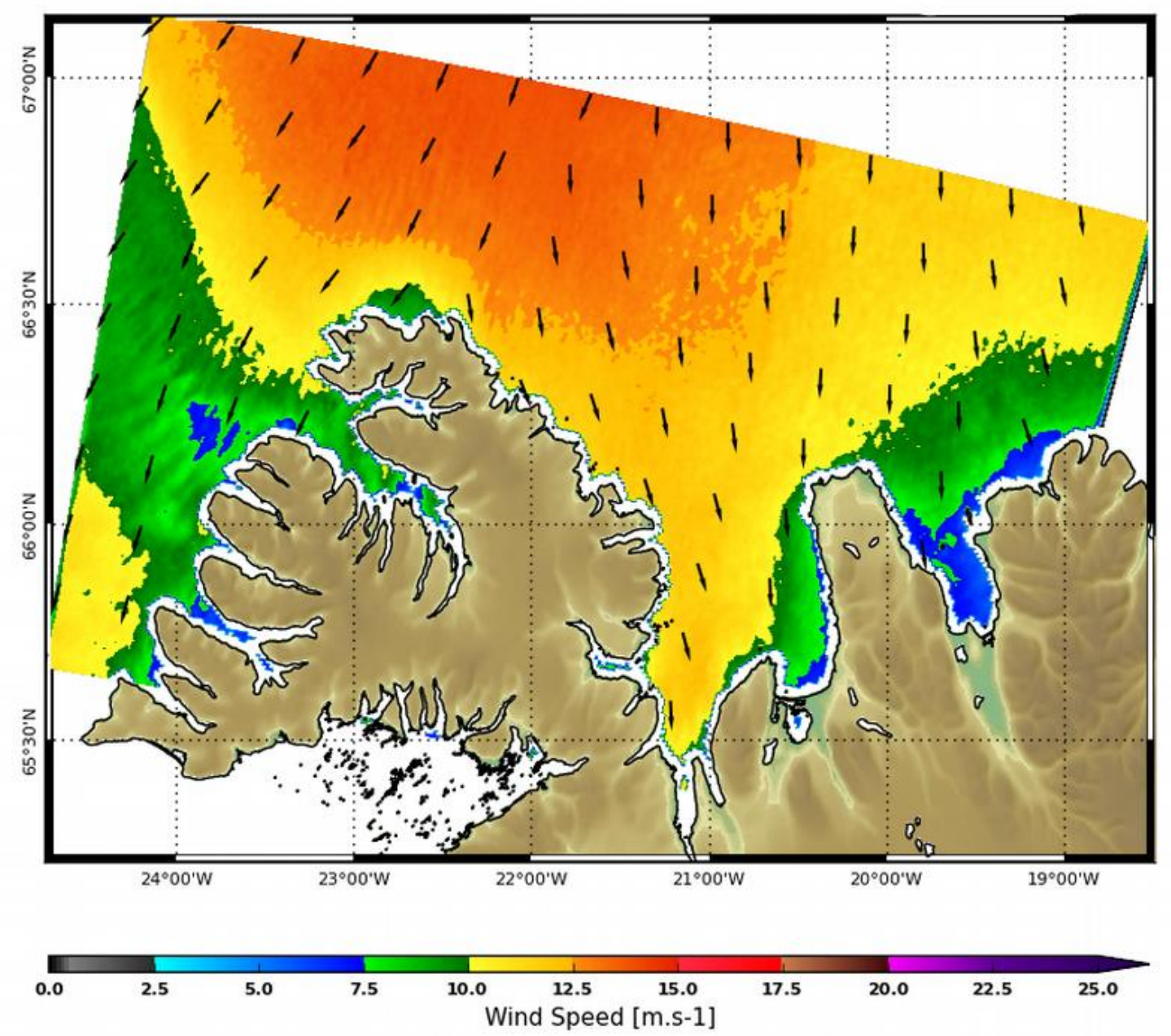

Figure 4. Coastal wind product around Denmark derived from Sentinel 1-A (mode IWS, polarization VV) acquired on 19 July 2015. Copernicus Sentinel data (2015)/ESA/CLS.

\section{Conclusions}

The recent World Economic Forum's Global Risks report [16] has listed climate change, water supply, and food shortage crises as three of the top five risks in terms of global impact and likelihood determined by 500+ experts from industry, government, academia, and civil society.

The ability of our society to manage these risks, adapt and become more resilient, depends to a large extent on our capacity to monitor, understand, and predict the state of our environment and the impact of human activities. While our impact on climate and water, food, and energy resources have often been addressed separately in terms of risk management, they in fact represent diverse but inextricably inter-connected facets of human-induced risk for our society. A new type of integrated "nexus" thinking is therefore needed to address climate problems in order to integrate multiple inter-related risks into a unified risk management framework.

Observations provide the foundation for such an integrated risk management approach. In particular, EO satellites orbiting hundreds of kilometers above the planet can play a key role here, as they "enlarge" our view of the climate system from the local to the global scale, and deliver the global, uniform (i.e., 
with one consistent set of instruments), and repetitive (e.g., with a rather high revisit rate) measurement of the ECVs needed to better quantify risks.

This unique role of EO is likely to grow significantly with the new generation of satellite missions providing enhanced spectral, temporal and spatial capabilities, delivering open, global, quality-controlled and multi-variate data sets (together with a measure of their uncertainty) needed to address some of the climate-related risks. In particular, the availability of operational Copernicus missions and services will be improved through the Sentinel missions under the European Copernicus initiative and guided by a full and open data policy. The advent of the Copernicus Climate Change Service is also likely to herald a new era of global and timely environmental information services, thereby creating new science and new applications in a broad market.

The challenge here is to make this new data revolution useful to improve people's lives. This challenge comes with a huge opportunity to improve resilience of our society. Meeting this challenge will require close dialogue between the various stakeholders, and in particular providers and users of climate information, to co-develop an integrated climate risk management approach and co-design associated technical and policy solutions.

\section{Conflicts of Interest}

The authors declare no conflict of interest.

\section{References}

1. Dobbs, R.; Oppenheim, J.; Thompson, F.; Brinkman, M.; Zornes, M. Resource Revolution: Meeting the World's Energy, Materials, Food and Water Needs; McKinsey \& Company: London, UK, 2011.

2. Crutzen, P.J. Geology of mankind: The anthropocene. Nature 2002, 415, doi:10.1038/415023a.

3. IPCC. Climate Change 2014: Mitigation of Climate Change. Contribution of Working Group III to the Fifth Assessment Report of the Intergovernmental Panel on Climate Change; Denhofer, O., Pichs-Madruga, R., Sokona, Y., Minx. J.C., Farahani, E., Kadner, S., Seyboth. K., Adler, A., Baum, I., Brunner, S., et al., Eds.; Cambridge University Press: New York, NY, USA, 2014.

4. IPCC. Managing the Risks of Extreme Events and Disasters to Advance Climate Change Adaptation. A Special Report of Working Groups I and II of the Intergovernmental Panel on Climate Change; Field, C.B., Barros, V., Stocker, T.F., Qin, D., Dokken, D.J., Ebi, K.L., Mastrandrea, M.D., Mach, K.J., Plattner, G.K., Allen, S.K., Tignor, M., Midgley, P.M., et al., Eds.; Cambridge University Press: New York, NY, USA, 2012.

5. World Bank Group. Turn Down the Heat: Why a $4{ }^{\circ} \mathrm{C}$ Warmer World Must Be Avoided; World Bank Group: Washington, DC, USA, 2012.

6. World Bank Group. Turn Down the Heat: Climate Extremes, Regional Impacts, and the Case for Resilience; World Bank Group: Washington, DC, USA, 2013.

7. United Nations. The Road to Dignity by 2030: Ending Poverty, Transforming All Lives and Protecting the Planet. United Nations: New York, NY, USA. 
8. Independent Expert Advisory Group on a Data Revolution for Sustainable Development. A World That Counts: Mobilising the Data Revolution for Sustainable Development. Available online: http://www.undatarevolution.org/wp-content/uploads/2014/11/A-World-That-Counts.pdf (accessed on 15 June 2015).

9. Merchant, C. J. Sea Surface Temperature during La Nina (October 1998). Available online: http://figshare.com/articles/Sea_surface_temperature_during_La_Nina_October_1998_/1524132 (accessed on 27 August 2015).

10. World Meteorological Organization. Climate Knowledge for Action: A Global Framework for Climate Services: Empowering the Most Vulnerable; World Meteorological Organization: Geneva, Switzerland, 2011.

11. Hallegatte, S.; Green, C.; Nicholls, R.J.; Corfee-Morlot, J. Future flood losses in major coastal cities. Nat. Clim. Change 2013, 3, 802-806.

12. Rogers, D.; Tsirkunov, V. Weather and Climate Resilience, Direction in Development; World Bank Group: Washington, DC, USA, 2013.

13. Word Bank Group. World Development Report: Risk and Opportunity; Word Bank Group: Washington, DC, USA, 2014.

14. US National Intelligence Council. Global Trends 2030: Alternative Worlds; US National Intelligence Council: Washington, DC, USA, 2013.

15. Food Early Solutions for Africa. FESA Micro-Insurance: Crop Insurance Reaching Every Farmer in Africa; EARS Earth Environment Monitoring: Delft, The Netherlands, 2014.

16. World Economic Forum. Global Risk Report; World Economic Forum: Geneva, Switzerland, 2015.

(C) 2015 by the authors; licensee MDPI, Basel, Switzerland. This article is an open access article distributed under the terms and conditions of the Creative Commons Attribution license (http://creativecommons.org/licenses/by/4.0/). 